\title{
Self-Harm: Cutting the Bad out of Me
}

\author{
Jennifer Harris
}

The practice of self-harm is increasing in the United Kingdom, accounting for the highest number of acute medical admissions for women. The medical and nursing response to repeaters, set within a climate of dwindling emergency and accident resources, has been one of impatience, frustration, and hostile care. The author undertook a correspondence study with 6 women who regularly self-harmed. The women claimed that medical and nursing professionals viewed their self-harm as irrational and illogical. However, a qualitative examination of the motivations and interests of all parties reveals that self-harm acts possess situated internal logic, whereas professionals tend to use rational logic in attempting to understand them.

\section{THE BACKGROUND TO THE STUDY}

Self-harm (or deliberate self-harm, as the medical literature defines it) has only recently achieved recognition within research literature as a set of practices that are distinct from suicidal acts (Giddens, 1971, p. xiv) or parasuicidal acts (Favazza, 1987, p. 270). Indeed, the process of establishing that the motivations behind acts of self-harm do not unproblematically form part of either of the latter fields has only come about in the past 10 years. Whereas this finding has complicated the picture for researchers and professionals in these fields, we have now reached a point where we recognize that although some acts may have suicidal or parasuicidal intent, there is a further body of acts that do not have this intent (Spandler, 1996, p. 2). There is currently very little known about these acts of self-harm, although there is evidence from British accident and emergency (A\&E) departments that taken as a whole, acts of self-harm are increasing (Department of Health and Social Security, 1984), that they are undertaken mainly during the night (Greenwood \& Bradley, 1997), and that the number of men engaged in these practices is increasing (see Temple, Harris, Patel, \& Bradley, in press).

The paucity of information concerning nonsuicidal and nonparasuicidal acts of self-harm appears to be the product of several related factors. First, there is the recent recognition that self-harm is a distinct field, as discussed above. Second, this very novelty has not yet filtered into the mainstream medical and nursing journals; consequently, the older ideas that linked self-harm firmly to suicide and parasuicide continue to abound. Third, the few studies being currently undertaken are primarily restricted to practitioners based within the mental health field. The latter are frequently viewed as locality studies, with findings deemed to be applicable only at a local level. These factors contribute to the view that self-harm is a minority 
concern, yet we can appreciate that there are obvious crucial funding implications for already overstretched A\&E services. Consultants in A\&E departments across the United Kingdom have started to become panicked by the enormous funding implications of self-harm behavior. Therefore, a majority of studies have aimed to $\log$ the rise in deliberate self-harm and isolate the precipitating factors without attempting to ascertain individual root causes or even explore the diversity of practices. Practitioner research has concentrated on damage limitation to overstretched medical services, which is fuelled by pecuniary reasoning (see Greenwood \& Bradley, 1997). For these reasons, the quantitative paradigm has been extensively used, not only because it appears to satisfy the medics' overweening positivist obsession with validity, reliability, and generalizability, but also because, more than these, it speaks in the commonly understood language of statistics.

As a qualitative researcher, I started from a very different premise. Why do so many women feel such considerable distress that they wish to harm themselves? What types of experiences have led the women to engage in self-harm? How can we make sense of self-harm as a reaction to intense emotional stress? Is there a "logic" to these acts?

\section{METHOD}

From the desire to understand the meaning of self-harm acts for women emerged the problem of gaining access to a sample. Given the sensitive nature of the topic and the way the field has been dominated by quantitative approaches, it seemed clear that face-to-face interviews would be difficult to arrange and harrowing for all participants. I felt that it was unnecessary for the purposes of this project to subject all parties to the interview process because I was primarily interested in understanding the contexts within which self-harm took place, and this could be achieved just as efficiently with letter writing.

I corresponded with a national organization for women who self-harm, one of which sent me the address for a pen pal network. I wrote to the coordinator, explaining my reasons for wishing to study this group, and she agreed to give my name and address to any interested parties. I told the coordinator that I would like to receive stories about the women's lives and any experiences of contact with A\&E departments. I received letters from 6 women, 2 of whom wrote once and 4 of whom wrote twice.

The letters were extremely detailed and covered the following subjects: personal characteristics; onset of self-harm; contact with A\&E staff; and reactions of family, friends, and the wider society, particularly to scars. The most difficult aspects of the study involved working out how to respond to the letters; how to express some of myself but balance empathy with the need to steer away from counseling or advice giving; how to project an opinion without in any way judging the letter writer; and how to draw boundaries between being honestly interested in practices and acts and appearing salacious.

The women in this study were between 20 and 45 years of age, and their ages at onset of self-harming ranged from 6 to 20 . The women reported self-harming for 5 to 39 years. None of the participants appeared to have stopped engaging in selfharming acts. Several women stated that they would prefer to stop self-harming but 
that they would find this extremely difficult. It seems that once women start on a path of self-harming, it is difficult for them to stop.

\section{ANALYZING THE BAD: SIGNIFICANT LIFE EVENTS}

Cutting into one's own flesh is obviously not something undertaken lightly. From the outset of the project, I was fascinated by the women's references to the bad. How did the bad get into the women's bodies in the first place? What form does the bad take, and how does it manifest itself?

At the age of 15 my father made me pregnant. I was told that I was going to have twins. [Female] died a few hours after she was born due to the deformity she suffered. [Male] was a good looking and healthy boy. I stayed with friends after he was born, and when he was 4 months old my father just turned up and took him. I was out at the time. I felt so much anger, pain and guilt. The one thing that had belonged to me had been taken. The emotional pain was so over powering I just couldn't stop myself from self-harming. I took tablets, alcohol and cut both my wrists. I was found and taken to hospital. I was put into a psychiatric unit where I found the doctors were unsympathetic and not very understanding of why I was self-harming. They told me that I was wasting their time and taking up a bed that someone else could be using. They did nothing to try to stop my self-harming in any way whatsoever. The hospital sent me to one of their hostels. I befriended someone called Fred. We used to go for drinks. Nothing else ever happened. Then one evening we met up with three of his friends. At the end of the evening I was forced into the back of Fred's van and I was repeatedly raped. The physical and emotional pain was so great I wished at the time that they would kill me to save me from all the pain I had to endure. Once back at the hostel Fred said that he would kill me if I told anyone what he and his friends had done. The pain inside me just seemed to grow and grow. I had to stop it in some way. Then I started to realise that every time I self-harmed I was trying to cut out all the bad inside me, most of all my father.

Analyzing this account produced the first clues concerning the nature of the bad. The first point to note is that the bad came into being following a significant life event. In this case, the bad (that is, the emotional pain) came into existence as a result of the woman's being raped by her father, Fred, and several complete strangers. Therefore, the bad is an externalized phenomenon that is called into existence and thereafter may take up residence within the women's bodies. The second clue is the motivational response to the existence of the bad, which is to cut it out. The Bible is littered with references to such behavior: "If your hand is your undoing, cut it off; it is better for you to enter into life maimed than to keep both hands and go to hell into unquenchable fire" (Mark 9:43). Indeed, Favazza (1987, p. 98) claims that this biblical passage has much to answer for in inspiring acts of self-harm. Whatever the truth of this claim, it seems clear that the women in this study use the bad as a metaphor for the wrongs of others, often abusers, sometimes rapists. Removing the bad helps the women to feel absolved:

After I have harmed myself, I feel a lot calmer and relaxed as if I've got the bad out. I usually do it at night and bandage myself up and curl up in bed. It helps me to fall asleep. I think it sort of comforts me. 
Having established the motivation, the next clue into the nature of the bad is found in the emotions present just before the women harm themselves. The women's descriptions of these emotions were always accompanied by explanations of benefits or release gained by their actions:

At the age of 6 the emotional pain became so great that all I wanted to do was end all
the pain. I hit the wall in my bedroom, and all the emotional pain just went. For the
first time I had found relief from this kind of pain. I found that physical pain or self-
harming became a normal part of my life. I found myself at school deliberately hurt-
ing myself, falling over in the playground or falling off apparatus in the gym. Doing
this I found relieved the emotional pain, and I received the warmth, love and atten-
tion that I had been looking for.

It appears that the women in this study used physical pain as a way to cope with emotional pain:

When I started to emerge from my anorexia, I needed some other way of dealing with the pain and hurt, so I started cutting instead. It is a way of gaining temporary relief. As the blood flows down the sink, so does the anger and the anguish. It's a way of transferring the scars and wounds inside onto a visible object, in my case my arm (once my leg and once my chest). It's easier to deal with it on the outside and it's a way of communicating the pain within.

This letter contains some interesting metaphorical imagery. Before I received the letter, I had read similar accounts in the literature, which in many ways seem to eulogize self-harm, to assign a particular symbolic significance to the letting of blood:

I turned and stabbed my own arm. It didn't break the skin and I kept going and going until it went through the skin and I pulled it out and all the blood started trickling down my arm and I just watched it and it felt like it was releasing the pressure in my head, like releasing all the bad blood and maggots. I knew it wasn't (maggots and stuff) but it was to me. (Spandler, 1996, p. 31)

In some circumstances then, projecting symbols is part of the release experienced in self-harm acts. The idea of communicating inner distress or rendering it visible to the self is a common theme throughout both the data in this study and the wider literature.

All the women had experienced very severe and distressing significant life events prior to commencing self-harm: usually emotional, physical, and/or sexual abuse.

Although all the women in the study now regularly cut themselves, they have also used anorexia, bulimia, and overdosing on prescribed medication to harm themselves.

\section{HOSTILE CARE IN A\&E DEPARTMENTS}

The women in this study have undergone traumatic and unpleasant incidents at A\&E departments following self-harm. I have called these incidents hostile care. The extent and nature of hostile care delivered to self-harm patients appears to be 
far more extreme than other forms of hostility directed toward patients in A\&E settings (see Akerstrom, 1997, p. 515). The most common form of hostile care experienced by the women was a lack of sympathy communicated by both doctors and nurses (Pritchard, 1995, p. 77):

I was put into a psychiatric unit where I found the doctors were unsympathetic and not very understanding of why I was self-harming. They told me that I was wasting their time and taking up a bed that someone else could be using. They did nothing to try to stop my self-harming in any way whatsoever.

In this account, we can see an element of hostile care that was reported by several other women in this study. This is the attempt to embarrass the patient, and it frequently revolves around the issue of time wasting. Put differently, the key to the stimulation of embarrassment is that the patient is unequivocally told she is not ill, and others are. She is wasting the A\&E staff's time and resources, and, furthermore, she is being selfish by not considering that other people are really ill: "The last time I went I was told, 'Don't you have anything better to do? Don't you think we've got enough to do with real emergencies?' " This evocation of embarrassment by the staff is practiced in such a way as to infantilize the patient. In other words, the object is to humiliate the patient by appealing to her sense of shame:

I was told off by nurses and the doctors. I just felt small. They do treat self-harmers different to accident people. We are classed as suicides .... The hospital staff just look at you as though you're wasting their time. That's how I felt.

There is widespread anger among the women in this study concerning their treatment at A\&E departments. Part of their anger stems from their "ritual humiliation" by the staff:

Got no help at all. All they wanted to do is pick on me like I was a naughty little girl, and it made me angry, and I couldn't open up at all for how they treated me. I just dreaded going to see them.

The time I went to A\&E, the staff on my mum's ward made me go. I knew as soon as I walked into the Doc's room it was going to be horrible. He shouted, "Why have you done this?" I just clammed up. The door was open and everyone was walking past and looking in. He kept shouting, "What is the reason for this, tell me the reason." I couldn't even look at him. He said to the nurse, "Get the psychiatrist on call," and I managed to say, "No." He asked me why, and I said, "Cos I'm not mentally ill." He laughed and said, "You tell me you're not mentally ill and you do this." Then he left and the nurse cleaned me up. A sister came to give me a tetanus and said I had to have it in my bum. I said I wanted it somewhere else and she said, "So you're refusing to have it done. I haven't time to argue with you, I'm busy enough" and walked out. I went then and felt 10 times worse.

The infantilizing process is clearly demonstrated in the account above. In fact, this participant uses the words "naughty little girl" for the way she was made to feel. She was abused, threatened, and, when she fought back, refused treatment. Indeed, the tenor of the text does not suggest a conversation between adults, let alone professional and patient. Hostile care relies on deep-seated emotions and the revival of ancient childhood memories. 


\section{THE LOGIC OF SELF-HARM}

Science does not hold all the answers to the ills of humanity, especially the emotional ills. We have become sophisticated, Internet-connected whiz kids in modern society, but, underneath the charade, we are still apes, creatures, animals. We symbolize, conceptualize, intellectualize (brainwork) to understand our own condition and attempt to convince ourselves that our decision-making processes are rational. As Rieff (1979) claims, Western thought suffers from its "irrational passion for dispassionate rationality" (p. 45). However, we also know that we are governed by our emotions, that a majority of our major life decisions have emotional bases, and that these processes do not employ rational logic. Some ailments, practices, and conditions are so much part of this nonrational logic that they can only be understood through the exploration of our emotional responses to our condition, cultural history, cultural artifacts, art forms, and narratives of ourselves and our own common sense understandings of how we became ourselves within this entity we call postmodern society (O'Brien \& Harris, 1999).

Self-harm can only be understood by referring to the cultural framework within which it is produced and by examining the cultural processes and practices within which it is contextualized. This is why the quantitative approach to self-harm, which inevitably aims to provide breadth at the expense of depth, fails to provide an explanation for self-harm. This is also the reason why a qualitative approach is implied. The women in this study have met with a complete lack of understanding about self-harm from medical and nursing staffs. However, it seems clear that the doctors and nurses find self-harm nonunderstandable because they are attempting to apply a rational scientific logic rather than a situated internal logic to the issue. This situated internal logic is discernible from the women's accounts, with each part of the logic resting on the previous tenet (see Table 1). To explain this divergence in logic, I will use as an example the issue of the release provided by cutting:

I really would like to stop self-harming but feel I can't because I am addicted to it. I couldn't live without the release it gives me. The buzz you get from it. If I could find a way of coping without harming myself, it would be fantastic.

One strong theme within the accounts relates to the release experienced and the consequential relief that the damage to the self is minor. A professional with a rationalist outlook cannot understand why a woman would cut herself and then be relieved. The women, however, describe being relieved that although they felt they had to cut themselves, they had not done it so badly that they would die as a result. It is in fact perfectly logical. The statements have their own situated internal logic, but it is not the logic of rationalists. Professionals have been consistently unable to grasp the situated internal logic of self-harm. The women actually state that they cut themselves to preserve life, yet professionals view this behavior as irrational because, to them, the act of cutting puts the woman's life in jeopardy. However, if you take the view that the act is inevitable, then the relief they experience is actually understandable in the terms with which they describe it: as "damage limitation" and as a form of life preservation.

The hostile care theory is only a partial explanation for divergence in the logic of the women in this study and the professionals at the A\&E departments. When we 
TABLE 1: The Logic of Self-Harm: Women's Emotions and the Professional View

\begin{tabular}{ll}
\hline Woman's Emotion Before/During Cutting & Professional's View: The Patient Must Be \\
\hline Low/pressured & Mentally ill to cut herself \\
Relief & Irrational to be relieved when she has cut herself \\
In control & Out of control to contemplate cutting herself \\
\hline
\end{tabular}

look deeper, it is evident that there is a serious miscommunication occurring between the parties involved. Table 1 explores the divergence of views on a cutting episode from the women's and the professionals' perspectives.

From the woman's point of view, cutting is a release, a way of gaining time out from emotional turmoil and unhappiness:

It starts off because you hate yourself. You feel dirty or angry with yourself. You get wound up, like a knot inside your stomach. You can hear your heart beating faster, harder, nothing seems real. You can't sit still; you feel like you're going to explode.

The relief that she experiences typically was thought by medics to be related to the production of enkephalins (that is, to have a biomedical base) (Favazza, 1987, p. 262). However, a social explanation can be detected from the women's descriptions in this study: "Putting the blade in your arm and cutting it, seeing the blood leak from your arm, it gives you such a release." What is the explanation for this release? One possible explanation is related to the women's descriptions of relief and control. This is where the logic of self-harm and the professional view completely diverge. The women state that they are in control when they self-harm. They cut to reinforce the fact of that control and to demonstrate it to themselves. However, the professional's view is that women who self-harm are out of control and, by association, mentally ill. Indeed, the professional believes that being out of control is a necessary prerequisite to the act of cutting. This paradox is graphically demonstrated in the following text:

Self-harm is all about emotions and dealing with them. It is not about being mentally ill, but the professionals just label us as mental. It is wrong. I am totally in control of my life and my self-harm. I am not a danger to either myself or anyone else. To me self-harm is the total opposite of suicide. I have never wanted or attempted to kill myself. It is all about coping. I do want to stop, but to be honest I don't know if I ever will 'cos its been a way of life for so long that I don't know if I could cope without it.

The logic of self-harm states that the release from emotional turmoil can be obtained by cutting the self; that this act is controlled in its extent; that the purpose of the act is to exert control over the body and the environment and to obtain relief; that a further purpose may be to translate emotional pain into physical pain; and that far from being a random and irrational act, cutting can be a means of limiting the damage to the self. The logic of the professionals attending the women in A\&E departments states that people in the main avoid injuring their bodies; therefore, anyone who deliberately inflicts pain on his or her body must be mentally ill or at 
least irrational. There can be no sense to the act, no way to rationalize its meaning. To undertake to cut the body must denote that the woman is out of control. Revisiting Table 1, it is possible to see how both the women's and the professionals' views are logical. But they are divergent, in both form and intent, and they lead to different assumptions concerning the motivations of the other party.

\section{THE SOCIAL CONTEXT OF WOMEN'S LIVES}

The uncaring attitude of A\&E staff further reinforces the feelings of emotional distress experienced by the women. At some point in their letters, all of the women describe complicated and ambivalent feelings toward their bodies, and the following text is particularly explicit on this point: "The medical profession don't understand you. To them you look normal but no one sees what's going in inside. I hate myself and I've never felt loved as a child or teen's or even now as an adult."

The lack of understanding, uncaring attitudes, and ritual humiliation experienced by the women only further these ambivalent feelings toward their bodies and confirm their lack of worth. If the medical and nursing professions seriously wish to retain resources and prevent self-harm, they must closely examine these issues and reconsider strategies toward these patients, not least because there is some evidence that distressing incidents such as these actually increase the likelihood of further harming:

When I've been down there [casualty] I've come out of there disgusted and when I got back home I've cut again.

I thought I couldn't take 73 tablets without any consequences, so I got in touch with my mother who phoned a GP to see if I needed any treatment .... The doctor sent an ambulance, and I went to A\&E. I clearly remember trying to explain that I wanted sleep (I'm an insomniac) and then kept taking them and that it became my intention to kill myself. His reply? He told me I'd have been better off overdosing on my Mogadon. (Incidentally, 2 weeks later I did.)

Four of the women explicitly state that they will never return to A\&E departments because of the treatment they have received. These women all describe very frequent self-harm in their letters. Inevitably, this means that they have had to devise a number of strategies to deal with the cuts:

The self-harm is bad at the moment. I'm going through blood arteries. I'm dealing with the wounds myself. I buy Steril Strips, Lint, wound pads and Tape. I buy everything to deal with the wounds. I just can't go back to the Casualty department.

When I have done, I would not got to hospital, partly because I hate them and I know doctors and nurses reactions on the whole are negative and I have heard lots of horror stories (no anaesthetic for stitches etc.).

As I have attempted to describe, there is an internal logic to self-harm that is different from, but just as valid as, the scientific rational logic of the medical profession. To understand the roots of the social contexts within which self-harm is situated, it is necessary to examine religious and cultural artifacts and edicts contained within our cultural heritages, particularly within religious texts. 


\section{RELIGIOUS EDICTS}

"When there is no feeling when you're dead inside, the pain, the blood, it proves I am alive. The blood is so red and beautiful and I can feel again."

What links do self-harm practices have with other facets of our cultural experiences of the social world? We need only look as far as religious and symbolic images contained within our cultural history to find some cues. Blood, or more particularly "lifeblood," is intensely symbolic. Take, for example, the image of Christ on the cross, his lifeblood draining away in crucifixion. The religious message that the image inspires is (ostensibly) that this man gave his life for his friends: He was prepared to die to save humanity from the same fate. Now, Christ's injuries were not self-inflicted, but there are curious parallels with the above statement.

Again, a rationalist would dismiss the logic here: How can we be saved by his blood, by the act of shedding blood on another's behalf? Of course, this makes sense as the supreme act of self-sacrifice if one is a Christian. Similarly, in Communion, believers are given red wine and told that it is Christ's blood. Now, in any other circumstance, not only would this appear illogical, it would also be regarded as cannibalistic. My point here is that it is the symbolism attached to the blood that carries overarching significance. Believers are not eating Christ's body and drinking his blood literally; they are performing these acts symbolically, within a belief system that encourages the practice as a way of reaffirming values and spirituality.

\section{CONCLUSION: THE SOUL IN PURGATORY}

Purging the self is the act of self-purification. Many of the women who self-harm also engage in purging their bodies of food (we now call this bulimia), and, as a result, many become anorexic. The act of starving the body (ritually or otherwise) has been rationalized as having a link with fashionable trends for attaining the perfect body (whatever that is), and this has, in modern society, reached epidemic proportions and is, by and large, a predominantly female condition. Famous women (for example, Princess Diana) who have been prone to eating disorders have also self-harmed (Spandler, 1996, p. 5).

There are real connections between the oppressive nature of modern society, the oppression of women, and their self-oppression. It is this that gives us a further cue to the nonrational behavior of self-harming women, many of whom state that they cut themselves to exercise control. To a rationalist, this behavior seems out of control, but, to a woman who is oppressed on all sides by society, the act of cutting is something she herself can control, perhaps the only thing she can control. Therefore, the behavior is understandable and possibly appropriate, given the circumstances in which it is produced.

Purgation means spiritual self-cleansing: It is literally the act of purifying the body to achieve a higher state of consciousness. Purgatory in the Catholic religion is the place that people go to when they die, "a place or state of temporary suffering or expiation" (Oxford English Dictionary, 1988, p. 837), the place where people must appease God and make amends for their sins. The temporary nature of the stay in this place implies that this is possible, that while there, the soul can be in some way 
purified and enter heaven. The definition also implies that purgatory is a "condition or place of spiritual purging especially of souls departing this life in grace of God but having to expiate venial sins" (Oxford English Dictionary, 1988, p. 837). Again, the terminology implies that an act of excusing is possible at this point. The soul can be cleansed, but a process must ensue.

It is not coincidental that the root meanings of the words purgation and purgatory are inextricably tied together: The act of self-cleansing (purgation) is symbolically and religiously linked to the state of temporary uncertainty over one's fate (purgatory). Within the context of self-harm and the hostile care meted out to women such as those in this study, purgatory seems a particularly appropriate metaphor, being a place where cries for help go unheard, where the logic and rationality of one's behavior is constantly questioned, and where the only certainty is that the suffering will continue.

\section{REFERENCES}

Akerstrom, M. (1997). Waiting: A source of hostile interaction in an emergency clinic. Qualitative Health Research, 7, 504-520.

Department of Health and Social Security. (1984). Management of deliberate self-harm (Tech. Rep. No. LA.SSL 84). London: Her Majesty's Stationery Office.

Favazza, A. (1987). Bodies under siege: Self-mutilation and body modification in culture and psychiatry. London: Johns Hopkins University Press.

Giddens, A. (1971). The sociology of suicide. London: Frank Cass.

Greenwood, S., \& Bradley, P. (1997). Managing deliberate self-harm: The A\&E perspective. Accident \& Emergency Nursing, 5, 134-136.

O’Brien, M., \& Harris, J. (1999). Modernity \& the politics of identity. In M. O'Brien, S. Penna, \& C. Hay (Eds.), Theorising modernity: Reflexivity, environment \& identity in Giddens' social theory (pp. 139-155). Essex, England: Addison Wesley Longman.

Oxford English Dictionary. (1988). Oxford, England: Oxford University Press.

Pritchard, C. (1995). Suicide-The ultimate rejection: A psychosocial study. Buckingham, England: Open University Press.

Rieff, P. (1979). Freud: The mind of a moralist. London: Chatto \& Windus.

Spandler, H. (1996). Who's hurting who? Young people, self-harm and suicide. Manchester, England: 42nd Street.

Temple, B., Harris, J., Patel, K., \& Bradley P. (in press). Gender \& self harm in Bradford Accident and Emergency Department. Manuscript submitted for publication.

Jennifer Harris, Ph.D., is a senior research fellow at the Social Policy Research Unit, University of York, United Kingdom. She has published widely in the fields of qualitative methodology and disability studies. She is the author of The Cultural Meaning of Deafness (1995), Deafness and the Hearing (1997), and "Surviving Ethnography: Coping With Violence, Anger \& Frustration" in the online serial The Qualitative Report (1997). 